\title{
Definition of Specific Functions and Procedural Skills Required by Cuban Specialists in Intensive Care and Emergency Medicine
}

\author{
Pedro L. Véliz MD MS, Esperanza M. Berra PhD, Ana R. Jorna MD MS
}

\begin{abstract}
INTRODUCTION Medical specialties' core curricula should take into account functions to be carried out, positions to be filled and populations to be served. The functions in the professional profile for specialty training of Cuban intensive care and emergency medicine specialists do not include all the activities that they actually perform in professional practice.
\end{abstract}

OBJECTIVE Define the specific functions and procedural skills required of Cuban specialists in intensive care and emergency medicine.

METHODS The study was conducted from April 2011 to September 2013. A three-stage methodological strategy was designed using qualitative techniques. By purposive maximum variation sampling, 82 professionals were selected. Documentary analysis and key informant criteria were used in the first stage. Two expert groups were formed in the second stage: one used various group techniques (focus group, oral and written brainstorming) and the second used a three-round Delphi method. In the final stage, a third group of experts was questioned in semistructured in-depth interviews, and a two-round Delphi method was employed to assess priorities.
RESULTS Ultimately, 78 specific functions were defined: $47(60.3 \%)$ patient care, $16(20.5 \%)$ managerial, $6(7.7 \%)$ teaching, and $9(11.5 \%)$ research. Thirty-one procedural skills were identified. The specific functions and procedural skills defined relate to the profession's requirements in clinical care of the critically ill, management of patient services, teaching and research at the specialist's different occupational levels.

CONCLUSIONS The specific functions and procedural skills required of intensive care and emergency medicine specialists were precisely identified by a scientific method. This product is key to improving the quality of teaching, research, administration and patient care in this specialty in Cuba. The specific functions and procedural skills identified are theoretical, practical, methodological and social contributions to inform future curricular reform and to help intensive care specialists enhance their performance in comprehensive patient care.

KEYWORDS Intensive care, urgent care, emergency medicine, continuing medical education, curriculum, diagnostic techniques and procedures, medical residency, Cuba

\section{INTRODUCTION}

Postgraduate specialty training enables university graduates to acquire, update, deepen and improve the professional competencies required by their jobs, in accordance with a country's needs for economic, social and cultural development. It is also intended to meet requirements of particular occupational profiles to achieve a high degree of professional development.[1] In medicine, specialty training is understood as building on undergraduate studies, as part of continuing and specialized medical education, essential to achieving high performance; solid social, ethical and moral principles; and excellent scientific and technical qualifications.

In Cuba, medical specialty curriculum design is formulated within a national framework, grounded in the country's history and culture. In accordance with the country's economic development and social needs, it is intended to link theory with practice, education with work, and patient care with research. It also includes other essential components such as management, teaching and research. Furthermore, the design is based on the concept of education as a guide for specialists-in-training to become independent and creative persons with values, knowledge and actions that contribute to cultural advancement in the context of cooperation and human solidarity.[2]

Curriculum development starts from a vision or model of the desired specialist, including values, personal qualities and philosophy. The professional profile provides specific guidelines for the educational process. It includes the profession's objective, as well as the functions and tasks the professional is expected to perform, the types of jobs to be filled, populations served, and the required skills and abilities that will be developed through training.[2,3]
The professional profile should be dynamic and mobile, in constant change and adjustment, responding to social demands; working conditions; and scientific, technological, ethical and sociological changes. This profile guides curriculum development in constant dialogue among educational institutions, workplace settings and professionals in the field, generating guidance for curricular adjustments.[3,4]

The term function is used in the context of the profession, position or job, to designate a person's set of duties and responsibilities. It arises from the very nature of the social process of work, allowing us to identify a profession's contribution to society.[5]

Intensive care medicine is a specialty characterized by its ability to dynamically identify and manage clinical situations of critically ill patients, requiring strict monitoring and use of special and immediate treatments. Since its emergence in the mid-20th century, it has undergone rapid scientific and technological changes. The specialty is now framed within a multidisciplinary context, demanding harmonious relationships among human, technological, pharmacological and architectural resources.[6]

Intensive care medicine started in Cuba in the late 1960s at the initiative of dedicated pediatricians, internists and anesthesiologists. Some intensive care units (ICU) were created in the 1970s in hospitals of major Cuban cities.[7,8] As a result of a dengue hemorrhagic fever epidemic in 1981,[8,9] several more ICUs were built and others remodeled and expanded. Complete modules of equipment, supplies and medications were acquired, and training was expedited to provide full-time specialists and nurses for these units. $[7,8]$ 
In the 1980s, the first Cuban texts on intensive care medicine were published. Specialists permanently engaged in intensive care were required to pass a national one-year course conducted in several ICUs accredited for teaching. Once they graduated, these specialists improved the level of intensive care provided and expanded it throughout the country.[7,8] In 1999, the specialty was officially created under the name of intensive care and emergency medicine (IEM). This combined intensive therapeutics and monitoring with emergency and urgent care[10] in a three-year residency with two profiles: adult and pediatric.[11]

In the first decade of the 21st century, the IEM specialty sphere expanded with the creation of municipal units for intensive care and life support in community-based polyclinics and municipalities that did not yet have hospital ICUs, increase in the specialized work of mobile medical emergency teams, creation of monovalent ICUs for cardiac and cerebrovascular diseases, and a distinction made in hospitals between urgent and emergency care. Simultaneously, Cuba increased its international solidarity with several countries seeking experienced IEM specialists for urgent care, emergency wards and ICUs. [6,12,13]

The core IEM curriculum for the current professional profile includes four basic functions: patient care, administration, teaching and research. These, in turn, are broken down into specific functions: 12 patient care, 2 administration, 5 teaching, and 3 research.[11] Since these do not encompass all activities performed by intensive care physicians in practice, the objective of this study was to derive a new definition of IEM specialists' specific functions and procedural skills, corresponding to current requirements of critically ill patients and related responsibilities.

\section{METHODS}

Study type and participants A developmental study was conducted throughout Cuba between April 2011 and September 2013, using qualitative techniques: questionnaires, interviews and consultations with experts.

Eighty-two professionals, including key informants and experts, were involved in different stages. A purposive maximum-variation sampling strategy was used to identify features common among participants; its strength lay in the selection of well-informed individuals, professionals whose opinions were backed by experience and who could provide authoritative and competent judgments.[14,15] Participants included members of the National IEM Expert Group; board members of the Cuban Society of Intensive Care and Emergency Medicine and presidents of its provincial chapters; the president and members of the IEM residency and specialty advisory committee; heads of several ICUs; IEM professors; officials of the Ministry of Public Health's (MINSAP) Department of Urgent Care, Emergency Medicine and Transplantation, who manage urgent ambulatory care, emergencies, intensive care, mobile medical emergency services and transplantation logistics in Cuba; as well as deans and vice deans with experience in academic training in medical faculties offering the IEM specialty.

Data sources and collection Instruments were developed for each method of collecting scientific evidence, and databases were created for statistical processing.

\section{Study variables}

IEM specialist Medical doctor who has successfully completed the IEM medical residency's academic program, or a professional in another medical specialty who has met requirements for receiving the title of second-degree specialist (a Cuban higher-level specialty credential) in IEM.[16]

Functions Set of activities, tasks, duties and responsibilities that determine the practice of a profession, position or employment.[5]

IEM specialists' specific functions The set of duties, responsibilities, activities and tasks that determine IEM specialist practice, classified within four general functions (patient care, administration, teaching and research).

IEM specialists' procedural skills Skills these specialists must utilize, according to one or more of the functions, and in which they perform technological procedures to provide direct medical care to critically ill patients.

Procedural skills were separated from specific functions, since procedures can apply to one or more functions.[5]

Study Design The algorithm used as a methodological strategy to define the specific functions and procedural skills required of IEM specialists (Figure 1) was developed in the three stages described below.

Stage 1: Identification of specific functions and procedural skills - Document review and analysis: Cuba's Postgraduate Education Regulations,[1] Regulation of Health Sciences Residency

Figure 1: Strategy for defining specific functions and procedural skills of Cuban IEM specialists

Stages

Steps

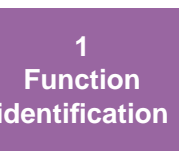

identification

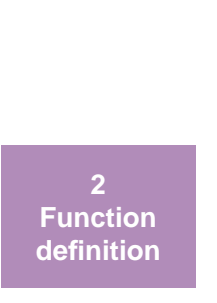

definition
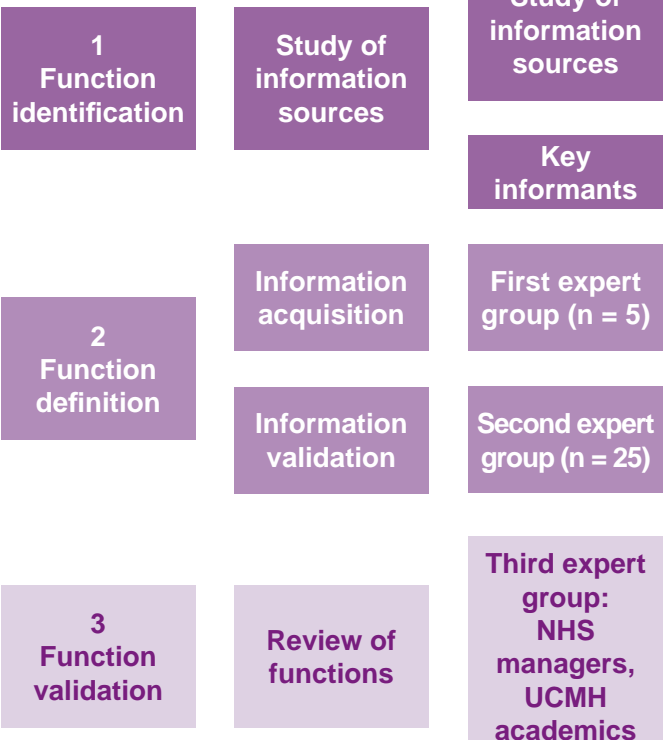

First expert

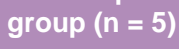

Study of

information

sources
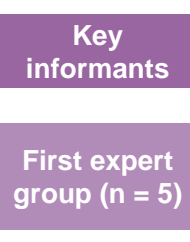

Third expert group: NHS

Review of functions managers

UCMH

academics

$(n=7)$
Techniques

Document

review and

analysis

Expert opinion

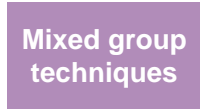

Delphi

EM: intensive care and emergency medicine NHS: National Health System UCMH: Medical University of Havana 
Regime,[17] Residency Program in Intensive Care and Emergency Medicine,[11] General Hospital Regulations,[18] General Polyclinic Regulations,[19] and documents of the Integrated Medical Emergency System (SIUM).

- Authors' participation in workshops and academic exchanges related to professional competencies and functions, held at the Academic Health Development Center (CEDAS) of the Medical University of Havana (UCMH).

- Opinion collection from key informants: two national workshops on the specialty were held, attended by members of the National IEM Expert Group; the national board of the Cuban Society of Intensive Care and Emergency Medicine and presidents of its provincial chapters; heads of ICUs; and IEM professors. This totaled 60 eminent IEM professionals. Primary information was obtained on the relevance and feasibility of the functions included in the current curriculum, in addition to proposals for new functions and procedural skills pertinent to IEM specialists' practice. During the workshops, agreement was reached on the need to redefine the functions, concluding that those already included in the curriculum did not correspond entirely with the specialty's level of development or with all duties that IEM specialists must now perform.

Stage 2: Definition of specific functions and procedural skills Information collection. This was done by a first group of experts composed of five professionals who took part in the two national specialty workshops and met the following requirements:

- At least ten years practicing IEM, currently involved in direct care

- Academic teaching appointment at assistant professor level or higher, with satisfactory evaluations

- MS or PhD relevant to IEM

- Second-degree specialization in IEM or wide recognition as a dedicated, respected intensive care specialist

- Performance over time of patient care, teaching and research responsibilities

These five experts employed several group techniques, including three two-hour focus group sessions.[20] These alternated with other techniques, such as oral and written brainstorming,[15] using a discussion list called Competenciasmie, created on Infomed (Cuba's digital health information network) for email communication. This enabled exchanges among participants without frequent meetings. In the end, a list of specific functions and procedural skills was obtained for our research objectives.

Information validation. This was done through a three-round Delphi process with a second expert group of 25 Cuban IEM professionals from across the country, following the methods described in detail by Véliz.[21]

Stage 3: Validation by NHS leaders and UCMH academics For this stage, a third expert group of 10 professionals was convened, consisting of senior managers who were policy, managerial, academic and methodological decisionmakers in Cuba's NHS and $\mathrm{UCMH}$. The purposes of the study were explained to all, as were their contributions and roles within it. A semistructured, in-depth interview was conducted with each about the IEM specialty curriculum and its practical implementation, and participants were asked to take part in a Delphi process. All participants had a competence coefficient of 0.9 or greater, considered very high.[22,23] Of the 10, 7 completed the Delphi method; the remaining 3 were excluded from the study.
For this Delphi process, the specific functions and procedural skills defined in the earlier phases were listed in a questionnaire, and a five-column or Likert-type rating scale was applied.[24] The seven participants were asked to rate the importance of each item by selecting one of the five columns: unimportant, slightly important, important, very important, and essential, with values of one to five in the same order. Two rounds of consultation were held and consensus obtained on the relative importance of the various functions.

Distribution tables were created with the four general functions and procedural skills as rows and the experts' answers as columns. The Friedman test was conducted to estimate the homogeneity of the experts' answers.

Data were collected in Excel and SPSS 21 for Windows databases, and descriptive statistical analysis was applied using absolute and relative values, contingency tables, and the Friedman test. In all cases, a confidence level of $95 \%$ was employed, pre-establishing the critical rejection level (alpha) as $p<0.05$. The information was summarized in statistical tables and texts.

The use of different qualitative techniques in the third group of experts to validate the information obtained by the two preceding groups allowed data triangulation and comparison of the different information sources.[25] Triangulation is an enriching tool that confers rigor, depth and complexity to a study and makes it possible to assign varying degrees of consistency to the findings, reducing bias and increasing understanding of phenomena under study.[26]

Ethics Participants' confidentiality, written informed consent and voluntariness were assured. Anonymity of individual opinions was guaranteed in shared summary feedback and final formulation of the Delphi processes. The study was approved by the ethics committee of UCMH's Comandante Manuel Fajardo Medical Sciences Faculty.

\section{RESULTS}

Stage 1 Key informants in the national workshops concluded that all functions in the current curriculum[11] were relevantsince they respond to societal needs, meet demands for health services, and are adaptable to institutional modernization processes. They considered that these functions can be efficiently and successfully carried out in practice, and adequate resources are available for the training, managerial, and leadership functions but not for patient care, mainly because some technological resources are lacking. The experts proposed 113 additional specific functions: 60 patient care, 21 managerial, 15 teaching and 17 research.

Stage 2 The first expert group worked on these proposals and the functions already in the program, bringing forward a total of 82 specific functions: 46 patient care, 14 managerial, 9 teaching, and 13 research. Many of the functions already in the curriculum remained on the list with little change: eight patient care, both managerial, all five teaching, and all three research functions. Patient care functions increased by 32 ; managerial by 12 ; teaching by 4 ; and research by 10 .

Forty-one procedural skills were defined, which we believe could be categorized further, and some are not specific to the 
specialty (although intensive care specialists may intervene via monitoring and control activities). In general, procedures performed by IEM specialists at all health care levels were included.

The results of the Delphi process with the second expert group are reported in detail by Véliz.[21] In sum, 31 procedural skills were established and 78 specific functions, namely, $47(60.3 \%)$ patient care, $16(20.5 \%)$ managerial, $6(7.7 \%)$ teaching, and 9 $(11.5 \%)$ research.

Stage 3 In interviews, the seven participants agreed that:

- The specialty curriculum must be changed in view of current knowledge and scientific and technological advances.

- Resident training should be better monitored, to ensure scientific and technical rigor.

- The current IEM residency rotations are still relevant and must be maintained, but new ones should be added to cover areas that will be part of the revised occupational profile.

- Training in prehospital urgencies and emergencies, coordination and management of mobile medical emergency teams, comprehensive trauma care, and other elements and skills of urgent care and emergency medicine should be strengthened in the residency, with rotations included.

- The one-year diploma course in intensive care should be eliminated.

- The IEM professional profile should respond to social needs, contain all the functions performed by the IEM specialist, list the required professional competencies, and encompass the range of occupational settings.

The opinions gathered through the interviews with experts support the relevance of this research as a first step toward future studies to inform reorganization of the IEM residency program.

The results of the Delphi questionnaire answered by the third expert group, regarding the degree of importance of each specific function, are shown in Table 1. Of 546 possible responses on the 78 functions defined by the previous groups, the 7 professionals rated 360 as essential (65.9\%); 132 very important (24.2\%), and 54 important (9.9\%). Among 217 possible responses regarding 31 procedural skills, 173 were rated as essential $(79.7 \%)$; 40 very important (18.4\%), and 4 important (1.8\%). No specific function or procedural skill was rated as slightly important or unimportant. Responses ranked mainly between very important and essential, with statistically significant differences in favor of these categories $(p<0.001)$. There was substantial agreement among experts regarding the important and very important responses (Friedman test $p<0.001$ ).

Table 1: Third-stage IEM-function validation by NHS managers and senior academics $(n=7)$

\begin{tabular}{|c|c|c|c|c|c|c|c|}
\hline \multirow{2}{*}{ Function } & \multicolumn{2}{|c|}{ Essential } & \multicolumn{2}{|c|}{ Very important } & \multicolumn{2}{|c|}{ Important } & \multirow{2}{*}{$\begin{array}{l}\text { Possible } \\
\text { answers* }\end{array}$} \\
\hline & $\mathrm{n}$ & $\%$ & $n$ & $\%$ & $\mathrm{n}$ & $\%$ & \\
\hline Patient care & 230 & 70.0 & 87 & 26.4 & 12 & 3.6 & 329 \\
\hline Managerial & 65 & 58.0 & 15 & 13.4 & 32 & 28.6 & 112 \\
\hline Teaching & 30 & 71.4 & 8 & 19.0 & 4 & 9.5 & 42 \\
\hline Research & 35 & 55.5 & 22 & 34.9 & 6 & 9.5 & 63 \\
\hline Total & 360 & 65.9 & 132 & 24.2 & 54 & 9.9 & 546 \\
\hline Procedural skills & 173 & 79.7 & 40 & 18.4 & 4 & 1.8 & 217 \\
\hline
\end{tabular}

${ }^{*} \mathrm{n} \times$ number of functions in category

IEM: intensive care and emergency medicine
The specific functions defined by the methodology used are shown in Table 2 and the procedural skills in Table 3.

\section{DISCUSSION}

This is the first Cuban study to define the specific functions and procedural skills required of IEM specialists in the current context. It clarifies the duties, tasks and activities that an IEM physician can and should perform in multiple work settings, which are more numerous and diverse today than they were when the specialty was created.

Defining functions enables increased productivity and rational use of personnel by promoting a more effective and productive organization; determining the duties, responsibilities and reporting relationships; improving interpersonal communication; and eliminating task duplication as well as jobs with insufficient content to fill the workday.[14]

Specific functions related to patient care predominated. This is consistent with Article 65 of the Residency Regime Regulation in Health Sciences,[17] because patient care is the essence of this specialty.

The newly defined patient care functions include those in the existing curriculum,[11] among which are providing comprehensive care, physician-patient-family relations, information and communication, teamwork, ethics, clinical monitoring and followup, management of artificial ventilation, vascular catheterization, vital life support, immediate and protocol-based treatment, determination of death, and life support of potential organ donors, as well as solving basic technical problems with medical equipment.

The patient care functions so defined are in accord with patientcentered care where the clinical method is vitally important, with continued observation to watch for new signs and monitor evolution of existing ones, exercise of full capacity to analyze and integrate new situations, clear and complete patient records that demonstrate clinical judgment and sound clinical reasoning to reach accurate diagnoses, appropriate drug regimens, and the judicious use of adjunct tests (in which technological advances do not replace diagnostic reasoning, that is, where technological advances in laboratory and imaging techniques are complementary to, not a substitute for, clinical acumen).[27] The new set of definitions emphasizes application of regulatory and clinical norms; ethical and legal aspects; timely detection and access, and early treatment of the critically ill patient in all health care sites[28] to prevent development of severe or irreversible complications; and teamwork, both in emergency or intensive care settings and in the integration of IEM specialists in multidisciplinary work groups. These new definitions do not negate the value of technological development. They encompass the various occupational profiles of the intensive care physician in Cuba, ranging from urgent, emergency and intensive care at all three health care levels of the NHS, to mobile emergency medical care and emergency care during disasters.

The new managerial functions defined include the two that were already in the specialty program. We believe that the increase by 14 is very important. It was based on the premise that administration is a social science aiming to achieve shared objectives and goals through plan- 
Table 2: Specific functions of IEM specialists (final product of three stages)

\section{PATIENT CARE}

1. In the system for care of seriously ill patients, give priority to health programs and continuous improvement of care.

2. Provide comprehensive medical care to patients with urgencies and emergencies and to critically ill patients, and implement immediate and protocol-based, stepped treatment according to the most advanced techniques and procedures available, prioritizing patients who are in immediate life-threatening danger.*

3. Care for patients' health in a personalized manner; respect their values, customs and beliefs; and ensure their care is in accordance with medical ethics.

4. Provide comprehensive health care, including primary and secondary prevention.

5. Establish and maintain good doctor-patient-family relations.

6. Keep patients and their families duly informed on patient health status during the medical interview and in medical reports, and whenever the need for new approaches, conducts or procedures arises.

7. Document in the patient record all information available on the problems identified, with emphasis on clinical reasoning and rationale for medical decisions.

8. Work in a team, complying with the institution's organizational and procedural handbooks as well as the goals of the team.

9. In an interdisciplinary approach, participate with other specialists in collective decision-making on severely ill patients.

10. Follow the principles established in the specialty care protocols and practice guidelines.

11. Ensure compliance with medical ethics and prevailing labor legislation, informed consent for medical procedures involving risk, and consensus decisionmaking.

12. Indicate, and on occasions perform, invasive clinical tests, laboratory, imaging and electrocardiographic studies; and interpret, consult and treat disorders so detected, as well as their complications.

13. Perform and control procedures for monitoring vital signs and invasive and noninvasive techniques of the specialty, as well as secondary complications.

14. Decide on placement and retention of tubes and drains, and control of related fluid intake and output.

15. Assess and monitor electrolyte balance as needed and perform medical actions after its interpretation.

16. Identify electrolyte and acid-base disorders; prescribe corrective action, ensure compliance and evaluate results.

17. Assess patient nutritional status on admission, implement and monitor nutritional balance and evaluate results.

18. Plan, indicate and monitor patient enteral nutrition by different methods and evaluate results.

19. Plan, indicate, control and comprehensively evaluate the process for adequate parenteral nutrition.

20. Perform deep vascular access, with standard techniques and according to patient care needs; diagnose and treat related complications.

21. Plan, indicate and control administration of intravenous fluids, using established techniques and the various equipment designed for this purpose.
22. Provide specialized care to the severely traumatized patient.

23. Ensure airway access by various standard techniques, in accordance with patient needs; adequately diagnose and treat complications.

24. Develop knowledge and skills for management, coordination and implementation of activities in the different scenarios included in the occupational profile.

25. Diagnose cardiorespiratory arrest and perform standard cardiopulmonary and cerebral resuscitation techniques, as well as postresuscitation care.

26. Organize, lead and act in disaster and mass casualty situations.

27. Satisfactorily carry out all the principles and techniques of artificial ventilation.

28. Maintain constant scientific and professional development, to apply the clinical method and assimilate challenges of new technologies and scientific advances.

29. Identify, diagnose and treat heart arrhythmias according to standard algorithms and protocols.

30. Diagnose, control and treat the patient with an acute vascular event.

31. Prevent, diagnose and treat conditions that cause acute organ failure.

32. Prevent, diagnose and treat severe decompensation of chronic organ conditions.

33. Prevent, diagnose and treat multiple organ dysfunction syndrome.

34. Comply with and enforce measures for prevention of health careassociated infections in critically ill patients.

35. Diagnose and treat all patients with sepsis and severe infections; apply comprehensive medical treatment according to established institutional policy.

36. Diagnose, treat and stabilize patients with high postoperative risk and complications, including organ and tissue transplantation patients.

37. Diagnose, treat and stabilize the critically ill obstetric patient.

38. Identify, evaluate and treat patients with acute life-threatening intoxications.

39. Diagnose and treat pain; apply analgesia, anesthesia and sedation techniques.

40. Indicate pharmacological treatment according to the process or condition, with expert knowledge of side effects, contraindications and interactions.

41. Diagnose death and prepare the corresponding legal documents.

42. Diagnose brain death and stabilize and maintain donor vital status.

43. Solve the most common technical problems arising in the operation of medical equipment, applying basic knowledge of the specialty.

44. Comply with the infection control system related to disinfection in all care units for critically ill patients.

45. Be familiar with the microbiological map of the institution and apply the correct antimicrobial policy.

46. Ensure safety and proper care during transportation of critically ill patients.

47. Use early-warning scales for hospitalized patients to ensure timely admission to ICU.

\section{MANAGERIAL}

1. Know and apply the organizational and functional structure of the unit and institution.

2. Implement and enforce compliance with the basic governing documents of the unit, such as organizational and procedures manuals, protocols and practice guidelines.

3. Plan, organize and manage medical care in the unit.

4. Supervise and advise nurses and technicians working in the unit.

5. Properly implement standards and criteria for admission, transfer and discharge in patient care units.

6. Efficiently plan, organize and control human and material resources, according to scope of responsibility.

7. Collaborate and work appropriately with other team members to achieve common objectives and create an environment of mutual support.

8. Interpret and use quality-of-care indicators for the critically ill patient aimed at effective and efficient medical attention.

9. Participate in or direct area or institution quality committees for evaluating the results of patient care.

10. Prepare work plans to comply with programs established for care of critically ill patients.

11. Participate in or lead meetings of the service, with emphasis on analysis of patient care and economic indicators. 
12. Be familiar with essential elements to evaluate professional competence, suitability and performance.

13. Prepare and monitor compliance with the individual development plan of every professional in the unit.

14. Be familiar with and/or execute the unit's and institution's human resource strategies, such as selection, education, development, training and employment.

15. Apply principles of strategic and participatory management by objectives in providing medical attention to critically ill patients.

16. Comply with and monitor compliance with patient safety programs.

\section{TEACHING}

1. Organize, direct and conduct teaching activities with undergraduate and postgraduate students, according to established profiles and learning objectives.

2. Develop basic teaching skills for planning and execution of teaching and training activities.

3. Select and use teaching methods that encourage active learning and develop independence and creativity.

\section{RESEARCH}

1. Apply the methodological principles of scientific research to planning, organization, implementation and monitoring of clinical research.

2. Conduct research related to problems of the specialty and those identified by the institution.

3. Organize scientific and research activities needed to advance knowledge and its dissemination, as well as to update the specialty.

4. Participate in implementation of clinical trials.
4. Apply various forms of evaluation of the teaching-learning process and analyze results.

5. Identify learning needs in the specialty that encourage continuing education for professionals and technicians working in progressive care wards for critically ill patients.

6. Be able to use new information technologies.

IEM: intensive care and emergency medicine

* See Table 3

\section{Table 3: Procedural skills in IEM (final product)}

1. Ensuring airway access and maintenance using various techniques

2. Oxygenation

3. Respiratory physiotherapy and postural drainage

4. Vascular access: arterial and venous

5. Measurement of systemic hemodynamic variables

6. Use of a defibrillator for cardiac arrhythmias

7. Cardiopulmonary and cerebral resuscitation

8. Peritoneal, abdominal, pleural, lumbar and pericardial punctures

9. Measurement of intra-abdominal and intracranial pressure

10. Extrarenal purification techniques

11. Management of different types of catheters and drains

12. Techniques for patient immobilization and transfer

13. Management of analgesia and sedation in critically ill patients

14. Temporary pacemaker placement

15. Mechanical ventilation management
5. Communicate research results in various formats.

6. Read medical literature in English to develop research and to update scientific knowledge.

7. Use basic statistical tools in developing research.

8. Direct research towards studies that lead to higher-level academic and research categories.

9. Design and participate in national and international multicenter studies.

IEM: intensive care and emergency medicine

ning, organizing, managing, coordinating and monitoring activities (by marshaling human and material resources to meet these organizational objectives), bearing in mind that quality and safety are paramount for the health care system.[29] In the context of health services delivery, enhancing quality and safety requires appropriate reorganization of teamwork, organizational structure, processfollowup and control; discussing and learning from errors; detecting potential risks; and evaluating results and indicators.[30] IEM specialists' duties also include supervising and advising nurses and technicians working in the wards; analyzing economic indicators; managing basic resources; and assessing the competence, suitability, and performance of subordinates; as well as developing and monitoring compliance with individual development plans of professionals under his or her direction.

Three of the six teaching functions arrived at were similar to those already in the curriculum: teaching methodologies for active
16. Electrocardiographic monitoring

17. Respiratory monitoring

18. Neurological monitoring

19. Sampling for gas analysis and interpretation of results

20. Assessment of nutritional status

21. Management of peritoneal washing and open-belly techniques

22. Management of ventricular procedural skills (includes intra-aortic balloon pump)

23. Control and monitoring of neuromuscular relaxation

24. Asepsis, cleanliness and sterility in all daily activities

25. Sampling for microbiological studies

26. Interpretation of unit microbiological maps

27. Application of tests to diagnose brain death

28. Application of prognostic scales to the critically ill patient

29. Removal from a vehicle and rescue of those injured

30. Performance of high, low and minimal pleuracotomy

31. Intraosseous solution administration and creative learning, evaluation techniques, and identification of learning needs that promote continuing education.[11] Based on the premise that the teaching function should be general, the functions defined emphasize the learning objectives for undergraduate and postgraduate students. The need to develop basic teaching skills for planning and implementing training activities was stressed, as was the use of new information technologies (which were not as developed and available when the IEM curriculum was originally drafted).

Concerning research functions, two of those in the program remained, with slight change, since application of methodological principles of scientific research must include not only planning and implementing clinical studies, but also their organization and monitoring. Likewise, the function of organizing scientific and research activities necessary to achieve knowledge, dissemination and updating of the specialty was separated from 
that of making objective critiques of scientific studies reviewed. Research on specialty- and institution-related issues confronted in daily practice[28] is considered essential for the specialty's development, as is participation in multicenter studies and clinical trials.

Procedural skills defined in our study are included in the IEM curriculum, either as methods, techniques or theoretical content.[11] We followed Torres' example[5] and separated procedural skills from specific functions, because procedures are conducted to fulfill different functions.

In Cuba, very few studies have been published on specific professional functions in the medical sciences[5,31] and thus, we cannot compare ours with previous ones exploring the same research objectives.

Intensive care medicine has experienced a rapid expansion in recent years throughout the world, but since national training programs differ widely,[28,32,33] comparisons are not easily made. The Competency-Based Training in Intensive Care Medicine in Europe study (CoBaTrICE) was an important effort to harmonize specialty curricula in Europe. Participants included organizations responsible for intensive care training in Europe and six other geographic regions.

First, a wide range of training programs, structures and processes for intensive care specialists was identified.[33] Subsequently, 102 specific competencies were distinguished within the 12 core competencies,[34] compatible with many European national programs and already implemented in many countries of the region. [32,35-37]

Elsewhere, in the USA, the Multisociety Task Force identified 276 specific competencies for pulmonary medicine and 327 for critical care medicine, starting points for changes in these specialties' curricula.[38]

We do not propose to compare our work with the CoBaTrICE international studies or other academic programs for several reasons:

- There is wide variability in national residency programs $[28,32,33,38]$ and in their implementation.[39]

- While elsewhere in the world, intensive care medicine and the urgent-care and emergency specialty have been clearly defined as two different clinical fields, in Cuba they are still part of a single specialty. The Cuban model focuses on continuous and progressive care of the patient with surgical or clinical urgencies and/or emergencies of any kind; the IEM specialist is trained to work in all scenarios through which the patient progresses, providing highly specialized care and treatment in all.[6]

- The curricula previously mentioned[28,32,33,38] have identified and defined the core and specific competencies of the specialty. These are conceived as a system of knowledge, skills, attitudes, and values that enable satisfactory performance in professional practice; $[3,20,40]$ while in our study, we have only defined the specific functions and procedural skills-as the set of duties, responsibilities, activities, tasks and procedures that determine the practice of this specialist in Cuba.

Our study's definition of patient care, managerial, teaching and research functions, together with procedural skills, constitutes the first stage of a methodological strategy to eventually identify, define, standardize and evaluate the professional competencies of the IEM specialist in Cuba in two future steps (first, identification and definition, then standardization and evaluation) to be undertaken by the National IEM Expert Group; and the Cuban Society of Intensive Care and Emergency Medicine.

Occupational, functional, and constructivist analyses[3,20,40] are among the several methods put forward to identify competencies, but the CEDAS workshop participants observed that the three methods overlap. Cuba's undergraduate and postgraduate programs set out professional expectations starting from functional analysis to identify competencies.[40]

Regarding the methodological strategy used, key informant opinions enabled us to explore the sustainability of the functions stated in the residency program and to provide a draft for consultation and expert review, taking into account that, in qualitative research, there is often overlap of the exploratory and the confirmatory phases. Its inductive and hypothesis-generating nature usually results in processes in which patterns observed in initial phases become clearer as the investigation progresses.[15]

A methodological strategy using qualitative techniques has proven effective in research. Its dialectical and participatory nature allows each stage to inform the following one. The use of various techniques by the first expert group enabled gathering of experts' views of the specialty and their experiences in the realities of clinical practice and teaching, as well as their suggestions for improving the resindency's academic program. Application of the Delphi method (described in detail in Véliz)[21] provided greater objectivity than in the previous group. And triangulation with the third expert group proved to be an efficient method for combining several methodological options (Delphi method and semistructured and in-depth interviews) to collect evidence supporting results of the previous two groups.

One limitation of this research is that definitions of several specific patient care functions are fairly generic, making it more difficult to assess them and to proceed to later phases in which specific competencies are defined for the Cuban IEM specialist. However, the study has considerable importance for professional practice because it defines, using a holistic approach, the actions, duties, obligations, activities, and technical skills required for the IEM specialist to meet the needs of Cuba's health system.

Thus, this research is useful because:

- It provides a better understanding of the functions, specific characteristics and scope of the IEM specialty in Cuba from a scientific perspective.

- It proposes more rational use of intensive care physicians in clinical practice and describes their role within the NHS.

- The definition of specific professional functions has methodological usefulness for developing managerial and educational interventions.

- The methodological strategy applied is a theoretical and technological contribution for future research to be conducted in IEM.

- It provides MINSAP with a product useful for revising documents governing the specialty program, several postgraduate programs, and intensive-care physician performance.

- It provides a starting point for identifying the full range of IEM specialist competencies. 
It has been recommended to MINSAP that these study results be included in the imminent reforms of the IEM specialty curriculum and in systematic evaluations of related services.

\section{CONCLUSIONS}

The scientifically derived specific functions and procedural skills of the IEM specialist constitute a tool to improve teaching, research, management and patient care in this specialty in Cuba. They are theoretical, practical, methodological and social contributions to future curriculum reform and for achieving better performance by IEM specialists in comprehensive patient care.

\section{ACKNOWLEDGMENTS}

The authors thank Dr Obdulio J. González Hernández for his advice and assistance in processing the data on which this paper is based. -1 -

\section{REFERENCES}

1. Ministry of Higher Education (CU). Reglamento de la Educación de Postgrado de la República de Cuba. Resolución Ministerial No. 132/2004. Havana: Ministry of Higher Education (CU); 2004. Spanish.

2. Castillo Guerrero LM, Nolla Cao N. Concepciones teóricas en el diseño curricular de las especialidades biomédicas. Educ Med Super [Internet]. 2004 Sep-Dec [cited 2013 Dec 29];18(4). Available from: http://scielo.sld.cu/ scielo.php?script=sci_arttext\&pid=S0864-2141 2004000400006\&lng=es. Spanish.

3. Salas Perea RS, Salas Mainegra A. Los modos de actuación profesional y su papel en la formación del médico. Rev Edumecentro [Internet]. 2014 May-Aug [cited 2014 Oct 13];6(2):6-30. Available from: http:// scielo.sld.cu/scielo.php?script=sci_arttext\&pid= S2077-28742014000200002\&lng=es. Spanish.

4. Hawes G, Corvalán O. Construcción de un perfil profesional. Universidad de Talca, Documento de trabajo 1/2004 [Internet]. Talca (CL): University of Talca (CL); 2005 [cited 2012 Jun 6]. 46 p. Available from: www.iide.cl/medios/iide/publica ciones/revistas/Construccion_de_un_Perfil_Pro fesional.pdf. Spanish.

5. Torres Esperón M. Definición de funciones de enfermería por niveles de formación. Propuesta para el Sistema de Salud Cubano [thesis]. [Havana]: National School of Public Health (CU); 2006. 71 p. Available from: http://tesis.repo.sld .cu/73/. Spanish

6. Véliz Martínez PL, Jorna Calixto AR. Evolución histórica y perspectivas futuras de la Medicina Intensiva y Emergencia como especialidad en Cuba. Educ Med Sup [Internet]. 2014 [cited 2014 Nov 1];28(3). Available from: http://ems.sld.cu/ index.php/ems/article/view/355/195. Spanish.

7. Caballero López A. Historia de los Cuidados Intensivos. Terapia Intensiva. 2nd ed. Havana: Editorial Ciencias Médicas; 2006. p. 3-10. Spanish.

8. Guzmán Rodríguez E, Guzmán Rubín E. Inicios de los cuidados intensivos pediátricos en Cuba y su evolución. Rev Cubana Pediatr. 2009;81 Suppl:42-7. Spanish.

9. Rodriguez-Roche R, Hinojosa Y, Guzmán MG. First dengue haemorrhagic fever epidemic in the Americas, 1981: insights into the causative agent. Arch Virol [Internet]. 2014 Aug 5 [cited 2014 Oct 8];159(12):3239-47. Available from: http://link .springer.com/article/10.1007\%2Fs00705-014 -2188-y

10. Parellada Blanco J. Medicina intensiva y emergencias: Una nueva especialidad. Rev Cub Med Mil [Internet]. 2001 Dec [cited 2014 Oct 9];30 Suppl 5;7-8. Available from: http://scielo.sld .cu/scielo.php?script=sci_arttext\&pid=S0138 $-65572001000500001 \&$ Ing $=$ es. Spanish.

11. Ministry of Public Health (CU). Programa de Especialización en Medicina Intensiva y Emergencia. Havana: Ministry of Public Health (CU); 1999. Spanish

12. Rodríguez Padrón $\mathrm{D}$, Moreno Montañez $\mathrm{M}$, Rodríguez Padrón J, Pérez Leyva E. Identificación de necesidades de aprendizaje sobre atención básica y de urgencias y emergencias médicas en la Atención Primaria de Salud. Educ Med Sup [Internet]. 2014 [cited 2014 Oct 8];28(1). Available from: http://ems.sld.cu/index .php/ems/article/view/333. Spanish.

13. Jorna Calixto AR, Véliz Martínez PL, Cuéllar Álvarez R. Infarto agudo de miocardio en los centros diagnósticos integrales de Vargas, Venezuela. Rev Cubana Med Gen Integr [Internet]. 2010 Oct-Dec [cited 2014 Oct 19];26(4):71220. Available from: http://scielo.sld.cu/scielo .php?script=sci_arttext\&pid=S0864-2125201000 0400014\&lng=es. Spanish.

14. Torres Esperón M. Metodología para definir funciones profesionales. Rev Cubana Salud Pública [Internet]. 2008 Oct-Dec [cited 2014 Mar 7];34(4). Available from: http://scielo.sld .cu/scielo.php?script=sci_arttext\&pid=S0864 $-34662008000400017 \&$ Ing=es. Spanish.

15. Artiles Visbal L, Iglesias Otero J, Barrios Osuna I. Metodología de la Investigación para las Ciencias de la Salud. Havana: Editorial Ciencias Médicas; 2009. Spanish.

16. Ministry of Public Health (CU). Reglamento para la obtención del segundo grado de las especialidades en ciencias de la salud. Resolución Ministerial No. 132/2009. Havana: Ministry of Public Health (CU); 2009. Spanish.

17. Ministry of Public Health (CU). Reglamento del Régimen de Residencia en Ciencias de la Salud. Resolución Ministerial No. 108/2004. Havana: Ministry of Public Health (CU); 2004. Spanish.

18. Ministry of Public Health (CU). Reglamento General de Hospitales. Resolución Ministerial 1/2007. Havana: Ministry of Public Health (CU); 2007. Spanish

19. Ministry of Public Health (CU). Reglamento General de Policlínicos. Resolución Ministerial No. 135/2008. Havana: Ministry of Public Health (CU); 2008. Spanish

20. Perdomo Victoria IT. Estrategia metodológica para evaluar competencias profesionales en especialistas de higiene y epidemiología [thesis] [Havana]: National School of Public Health (CU); 2007. 64 p. Available from: http://tesis.repo.sld .cu/74/. Spanish.

21. Véliz Martínez PL, Berra Socarrás EM, Jorna Calixto AR, Sabina Martínez RR. Aplicación del método Delphi para la definición de funciones del especialista en medicina intensiva y emergencia. Rev Cubana Med Intens Emerg [Internet]. 2013 [cited 2015 Mar 18];12(2). Available from en: http://bvs.sld.cu/revistas/mie/vol12_2_13/mie 03213.html. Spanish.

22. Zartha Sossa JW, Montes Hincapié JM, Toro Jaramillo ID, Villada HS. Método Delphi - Propuesta para el cálculo del número de expertos en un estudio Delphi sobre empaques biodegradables al 2032. Espacios [Internet]. 2014 Oct 2 [cited 2015 Mar 10];35(13):10. Available from: http://www.revistaespacios.com/ a14v35n13/14351310.html. Spanish.

23. Cabero Almenara J, Infante Moro A. Empleo del método delphi y su empleo en la investigación en comunicación y educación. EDUTEC [Internet] 2014 Jun [cited 2015 Mar 10];48. Available from:
http://edutec.rediris.es/Revelec2/Revelec48/pdf/ Edutec-e_n48_Cabero-Infante.pdf. Spanish.

24. García Valdés M, Suárez Marín M. El método Delphi para la consulta a expertos en la investigación científica. Rev Cubana Salud Pública [Internet]. 2013 Apr-Jun [cited 2013 Dec 29];39(2):253-67. Available from: http://scielo .sld.cu/scielo.php?script=sci_arttext\&pid=S0864 $-34662013000200007 \&$ Ing=es. Spanish.

25. Vera A, Villalón C. La triangulación entre métodos cuantitativos y cualitativos en el proceso de investigación. Ciencia \& Trabajo [Internet]. 2005 Apr-Jun [cited 2014 Apr 26];7(16):85-7. Available from: http://www.cienciaytrabajo.cl/pdfs/16/ Pagina\%2085.pdf. Spanish.

26. Okuda Benavides M, Gómez-Restrepo C. Métodos en investigación cualitativa: triangulación Rev Colombiana Psiquiat [Internet]. 2005 [cited 2014 Apr 26];34(1):118-24. Available from: http://www.redalyc.org/pdf/806/80628403009 .pdf. Spanish.

27. Espinosa Brito A, Rocha Hernández JF. Medicina clínica para intensivistas. Preguntas a un experto. Rev Cubana Med Intens Emerg [Internet]. 2007 [cited 2012 May 16];6(4):934-50. Available from: http://bvs.sld.cu/revistas/mie/vol6 4 _ 07/ mie09407.htm. Spanish.

28. Blanch L, Annane D, Antonelli M, Chiche JD, Cuñat J, Girard TD, et al. The future of intensive care medicine. Med Intensiva. 2013 Mar;37(2):91-8.

29. Hernández Ortiz J, Gómez Torres D. Una aproximación al concepto de gerencia y administración aplicado a la disciplina de enfermería. Esc Anna Nery [Internet]. 2010 Jul-Sep [cited 2014 Apr 26];14(3):625-32. Available from: http://www scielo.br/pdf/ean/v14n3/v14n3a27.pdf. Spanish.

30. Romero CM. Seguridad y calidad en Medicina Intensiva. Med Intensiva [Internet]. 2009 Oct [cited 2014 Apr 26];33(7):346-52. Available from: http://www.medintensiva.org/es/ seguridad-calidad-medicina-intensiva/articulo/ S0210569109000060/. Spanish

31. González Marrero A, Pérez Silva T, Oliva Oliva E, Álvarez Porben S, Rodríguez Mancebo G, Arredondo Naite OF, et al. Funciones específicas del personal de enfermería ocupacional en Cuba. Rev Cubana Salud Trab. 2010;11(2):5963. Spanish.

32. Bion J, Rothen HU. Models for intensive care training. A European perspective. Am J Respir Crit Care Med [Internet]. 2014 Feb 1 [cited 2014 Oct 23];189(3):256-62. Available from: http://www.atsjournals.org/doi/abs/10.1164/ rccm.201311-2058CP

33. Barret $\mathrm{H}$, Bion JF. An international survey of training in adult intensive medicine. Intensive Care Med. 2005 Apr;31(4):553-61.

34. CoBaTrICE Collaboration; Bion JF, Barrett $\mathrm{H}$. Development of core competencies for an international training programme in intensive care medicine. Intensive Care Med. 2006 Sep;32(9):1371-83.

35. The CoBaTrICE Collaboration. The educational environment for training in intensive care 
medicine: structures, processes, outcomes and challenges in the European region. Intensive Care Med [Internet]. 2009 Sep 23 [cited 2014 Oct 23];35(9):1575-83. Available from: http://link.springer.com/article/10.1007\%2 Fs00134-009-1514-4

36. The CoBaTrICE Collaboration. International standards for programmes of training in intensive care medicine in Europe. Intensive Care Med [Internet]. 2011 Mar [cited 2014 Oct 23];37(3):385-93. Available from: http://link .springer.com/article/10.1007\%2Fs00134-010 -2096-x

37. Castellanos-Ortega A, Rothen HU, Franco N, Rayo LA, Martín-Loeches I, Ramírez P, et al. Formación en Medicina Intensiva. Un reto a nuestro alcance. Med Intensiva [Internet]. 2014 Jun-Jul [cited 2014 Oct 23];38(5):305-10. Available from: http://www.medintensiva.org/es/ formacion-medicina-intensiva-un-reto/articulo/ S0210569114000175/. Spanish.

38. Buckley JD, Addrizzo-Harris DJ, Clay AS, Curtis JR, Kotloff RM, Lorin SM, et al. Multisociety task force recommendations of competencies in pul- monary and critical care medicine. Am J Respir Crit Care Med [Internet]. 2009 Aug 15 [cited 2014 Oct 23];180(4):290-5. Available from: http://www .atsjournals.org/doi/full/10.1164/rccm.200904 -0521ST\#.Us0Ydfsvm 0

39. Vázquez Guillamet $\bar{R}$. Aspectos a conocer de la medicina intensiva en Estados Unidos. Med Intensiva [Internet]. 2013 Jun-Jul [cited 2014 Oct 23];37(5):339-42. Available from: http://www.medintensiva.org/es/aspectos-cono cer-medicina-intensiva-estados/articulo/S02 10569113000491/. Spanish.

40. Ortiz García M, Cires Reyes E. Diseño curricula por competencias. Aplicación al macrocurrículo. Rev Edumecentro [Internet]. 2012 Jan-Apr [cited 2014 Oct 13];4(1):10-7. Available from: http:// www.edumecentro.sld.cu/pag/Vol4\%281\%29/ PDF/Vol4_num1_04.pdf. Spanish.

\section{THE AUTHORS}

Pedro L. Véliz Martínez (Corresponding author: urgrav@infomed.sld.cu), dual specialist in internal medicine and intensive care/emer- gency medicine, with master's degrees in medical urgencies and medical education. Associate professor and researcher, Medical University of Havana (UCMH), Havana, Cuba.

Esperanza M. Berra Socarrás, academic with doctorate in pedagogical sciences. Full professor and senior researcher, Manuel Fajardo Faculty of Medical Sciences (FCMMF), UCMH, Havana, Cuba.

Ana R. Jorna Calixto, family physician with master's degree in health nutrition. Associate professor and adjunct researcher, FCMMF, UCMH, Havana, Cuba.

Submitted: January 8, 2014

Approved for publication: June 27, 2015

Disclosures: None 